\title{
DNA-Protein Interaction
}

National Cancer Institute

\section{Source}

National Cancer Institute. DNA-Protein Interaction. NCI Thesaurus. Code C18755.

The biochemical and biophysical properties governing the binding of proteins to DNA 